\title{
Report
}

\section{Attention PCP's: The Prior Inpatient Post-MI Complications Are Now More Likely to Present to Your Outpatient Clinic}

\author{
Maria Jose Zabala Ramirez, Robert Lichtenberg \\ Loyola - MacNeal Internal Medicine Residency, MacNeal Hospital, Berwyn, USA \\ Email address: \\ MariaJose.ZabalaRamirez@lumc.edu (M. J. Z. Ramirez)
}

\section{To cite this article:}

Maria Jose Zabala Ramirez, Robert Lichtenberg. Attention PCP's: The Prior Inpatient Post-MI Complications Are Now More Likely to Present to Your Outpatient Clinic. American Journal of Internal Medicine. Vol. 8, No. 3, 2020, pp. 113-120. doi: 10.11648/j.ajim.20200803.14

Received: April 14, 2020; Accepted: April 29, 2020; Published: May 15, 2020

\begin{abstract}
Cardiovascular disease is one of the leading causes of hospitalization and death in the United States. Every 40 seconds an acute myocardial infarction occurs. Most of the mortality occurs before the patient can reach medical care. Those that do reach medical care have seen a dramatic improvement in survival. The American Heart Association 2019 heart disease and stroke statistics from 2006 to 2016 show that the death rate has decreased by $31.8 \%$. This decrease in mortality is multifactorial starting with enhanced public awareness of the early signs of myocardial infarction with mobilization of first responders, rapid reperfusion therapy and improved medical care. These improvements have resulted in a decrease in the mechanical complications of left ventricular rupture, acquired ventricular septal defect and papillary muscle rupture. However, these have not been eliminated and due to the shorter hospital stay after an MI with their peak incidence occurring more than 3 days post infarction has resulted in a change in the presentation of these complications. It was not that long ago that the usual length of stay for what was called a transmural MI or Q -wave MI was 21 days and a sub-endocardial or non-Q wave 10 days. This duration of observation made the presentation of post myocardial mechanical complications an in-hospital diagnosis. However, now in the era of reperfusion for both STEMI and NSTEMI, it is uncommon to see a length of stay longer than 3 days. While this early discharge practice has been shown to be safe, it shifts the diagnosis and treatment of post MI complications to the outpatient clinic where the Primary Care Provider (PCP) may be the first to see the patient post discharge. This paper will review the three most common mechanical complications that occur post $\mathrm{MI}$ and provide keys to their diagnosis and triage.
\end{abstract}

Keywords: Post MI Mechanical Complications, Acquired Ventricular Septal Defect, Papillary Muscle Rupture, Left Ventricular Free Wall Rupture

\section{Introduction}

Mechanical complications following a myocardial infarction include left ventricular rupture, acquired ventricular septal defect and papillary muscle rupture. Historically, they have an extremely high mortality exceeding $90 \%$ without surgical intervention [1-3]. Their incidence in the era of reperfusion therapy is $<1 \%$ however, once present continue to be associated with a markedly increased mortality (Figure 1) [4]. They are seen when significant myocardial necrosis occurs and once present are associated with rapid deterioration. Myocardial necrosis in the setting of an acute myocardial infarction is due to several etiologies including late presentation, delayed, incomplete or failed reperfusion. Prior to reperfusion therapy, these complications would present on post MI days 3-21. Historically, it was noted by Herrick and Levine that following a myocardial infarction if one did not rest, the incidence of myocardial rupture and death was 4-5 times higher than those patients who were confined to bed and hospitalized for several months [5, 6]. In the 1970's hospital duration shortened to 21 days for transmural Q wave MI and 10 days for sub-endothelial-non-Q wave infarctions. Earlier and earlier mobilization and discharge were proven safe and the hospital duration progressively shortened. Currently the duration of hospitalization rarely exceeds 3 days [7]. What has not changed is the timing of mechanical complications with their presentation after Day 3 post MI and thus post discharge. Discharge instructions include scheduling a transitional care visit within the next week with both their PCP and 
Cardiologist. The patient may also call with question regarding new symptoms and the PCP should be aware of those that would warrant urgent evaluation. If being seen in the office there are historical clues, key exam and ECG findings with which the primary care physician should be familiar. The key to patient survival is rapid identification and triage for emergent evaluation and surgery. This paper will report 3 cases demonstrating the common and potentially fatal mechanical complications that now are more likely to be seen in the outpatient setting and provide clues to their detection.

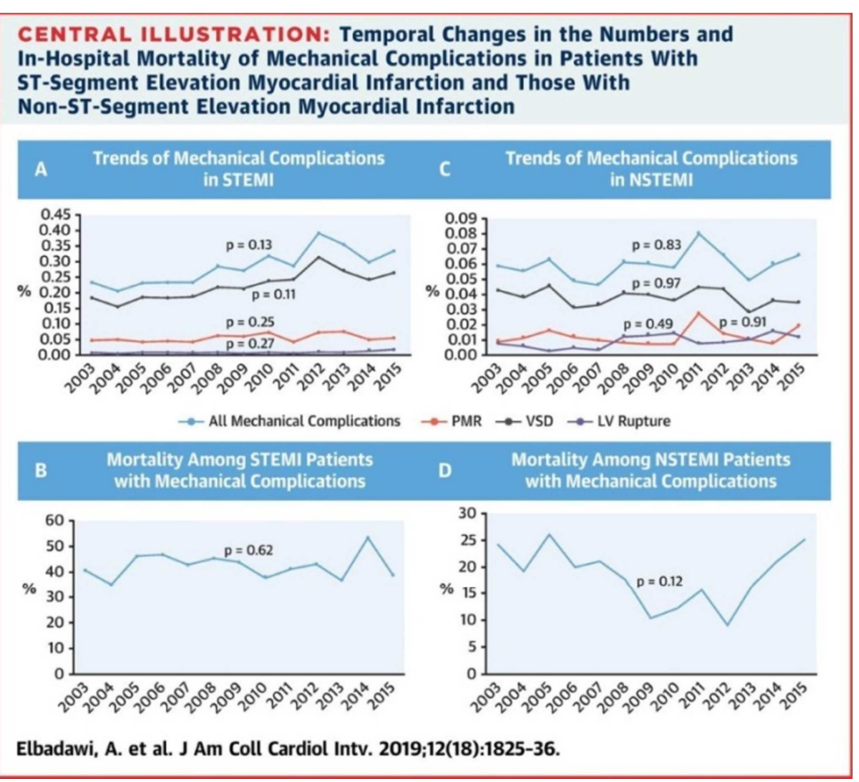

Figure 1. In the ST-segment elevation myocardial infarction (STEMI) cohort, there was no changes in the rates of (A) mechanical complications $(0.23 \%$ in 2003 vs $0.30 \%$ in 2015; $p=0.13$ ) and (B) in-hospital mortality among those with mechanical complications $(40.5 \%$ in 2003 vs $38.7 \%$ in 2015; $p=0.62$ ). In the non-ST-segment elevation myocardial infarction (NSTEMI) cohort, there was no change in the rates of (C) mechanical complications $(0.06 \%$ in $2003 \mathrm{vS} 0.07 \%$ in 2015; $p=0.83)$ and $(D)$ in-hospital mortality among those with mechanical complications $(24.1 \%$ in 2003 vs $25.0 \%$ in 2015; p0.12). LV=left ventricular, PMR = papillary muscle rupture, VSD = ventricular septal defect. (Reference 4: Reproduced with permission).

\section{Cases}

\subsection{Case \#1}

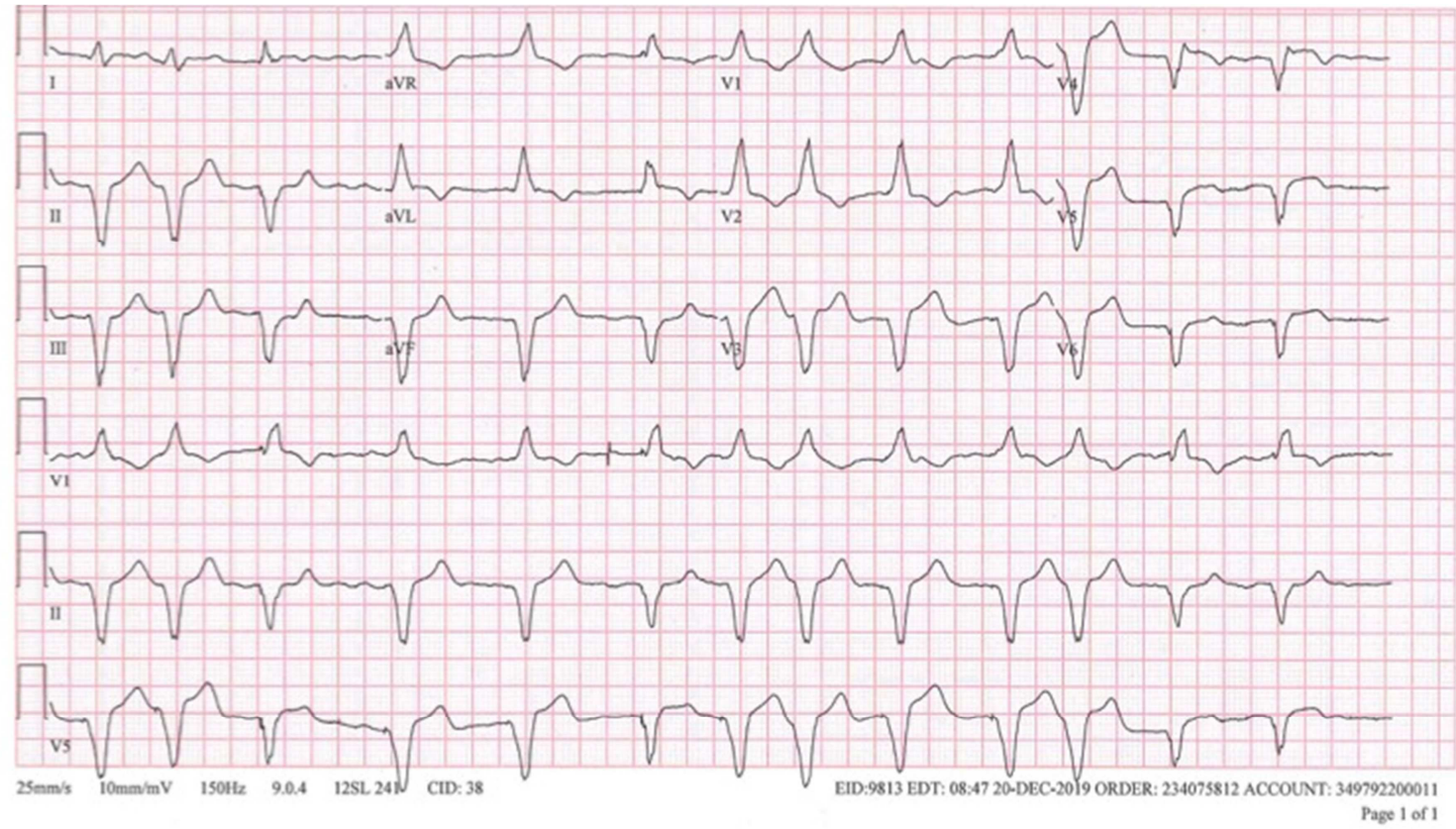

Figure 2. ECG: In addition to atrial fibrillation it shows a complete RBBB with left axis deviation consistent with bi-fascicular block and most importantly $Q$ waves in V4 - V6 suggesting an already infarcted segment of the anterior wall. 
Ninety-one-year-old male presented with a one-week history of constant left shoulder pain and 12 hours of acute onset of shortness prior. He became confused, with speech that was slurred and slower than normal. Past medical history remarkable included type $2 \mathrm{DM}$ of 3 years duration, atrial fibrillation with AVN ablation and VVI pacemaker, myasthenia gravis, and history of gastrointestinal bleed while on anticoagulation. In the emergency room (ER) stroke alert was called. His NIH score was Zero and an immediate CT of the head without acute findings. His mental status was normal on arrival to the ER and his exam revealed a BP 85-100/68-85, irregularly, irregular rhythm 70-110/min, RR 22-30, saturations $92 \%$ on room air. He appeared to be in moderate respiratory distress with distended JVP to the angle of the jaw at 60 degrees. Lung exam had bilateral rales, and his heart sounds were distant and soft with a low-pitched early systolic murmur. His Point of Care Troponin I was $>32$ (upper limit of assay) and his ECG shown (Figure 2). His symptoms rapidly progressed over the next hour. A stat bedside echo revealed a large distal septal ventricular septal defect (VSD)(Figure 3). The patient was decisional and after discussing his problem and prognosis, he elected for comfort care. He expired within 2 hours of presentation.

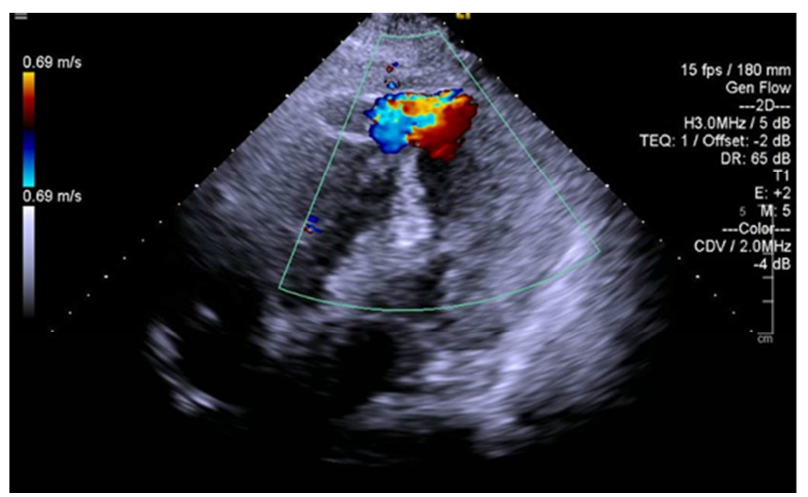

Figure 3. Echocardiogram with color Doppler. Apical view with shunt seen at the apical segment of the ventricular septum.
Clues for the PCP for the diagnosis of a mechanical complication in this setting:

1. History: Duration of symptoms prior to initial presentation: One week

2. Exam with elevated JVP, pulmonary rales and systolic murmur

3. ECG with pathologic $\mathrm{Q}$ waves, no $\mathrm{R}$ waves across the anterior wall from V3 -V6 indicating a completed infarction of several days duration

4. Markedly elevated presenting Troponin suggesting already significant myocardial necrosis.

\subsection{Case \#2}

Seventy-four-year-old female presented to her PCP with 5 days of chest pain and two syncopal episodes in the last 24 hours. She appeared uncomfortable, restless and agitated with a BP of 94/70, HR 102, RR 24, 94\% on room air. Normal JVP, lungs clear and the PMI was not displaced but an apical gallop rhythm noted but no pathologic murmur or rub was heard. Office ECG was performed (Figure 4) and 911 called. In the emergency department she was found to have a systolic blood pressure in the $60 \mathrm{~s}$. She was taken directly to the cardiac cath lab where an intra-aortic balloon pump was placed followed by angiography revealing single vessel CAD with a $100 \%$ occluded non-dominant circumflex vessel. Catheter based revascularization of the occluded artery was successfully performed. A left ventriculogram revealed preserved global left ventricular systolic function with an EF of $50-55 \%$ but the lateral wall was akinetic. In addition, a small area of extravasation of dye was noted from the LV cavity (Figure 5). A stat bedside transesophageal echocardiogram revealed disruption of the lateral wall with a small pericardial effusion (Figure 6). The patient was taken for emergent surgery and repair of ventricular rupture (Figure 7).

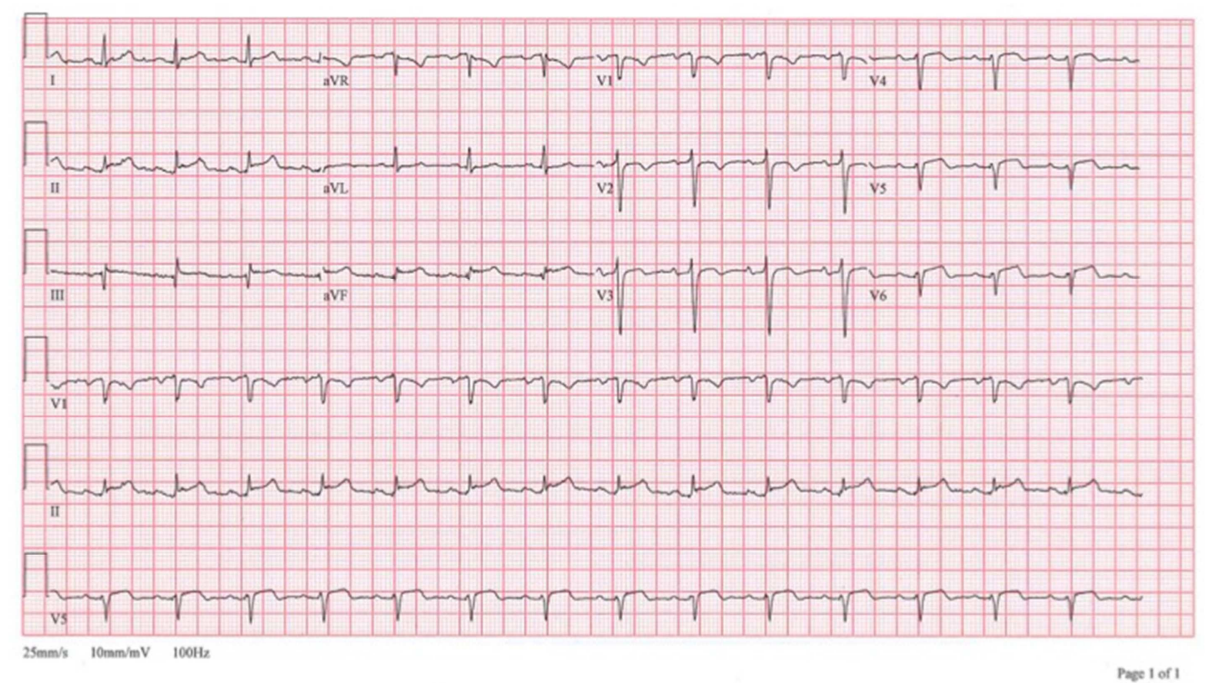

Figure 4. EKG showing significant $Q$ waves inferior leads and loss of $R$ wave V4 - V6 indicating component of infarcted myocardium. 


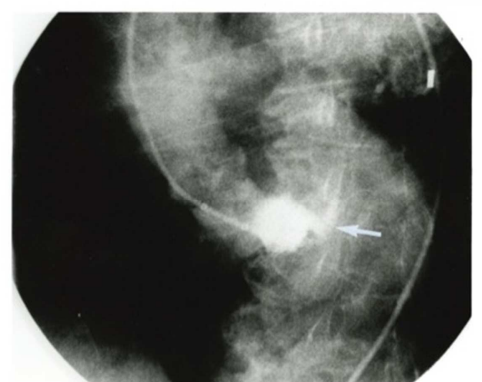

Figure 5. LAO ventriculogram showing extravasation of dye from the lateral wall of the left ventricle.

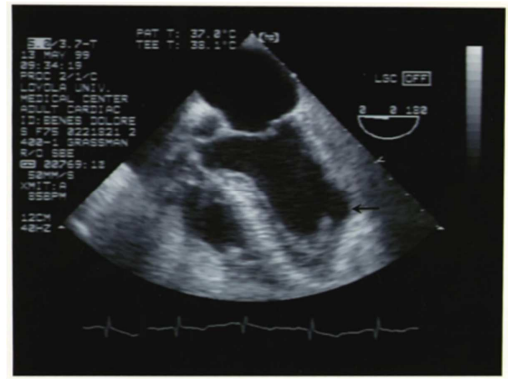

Figure 6. TEE view showing the focal defect in the lateral wall of the left ventricle.

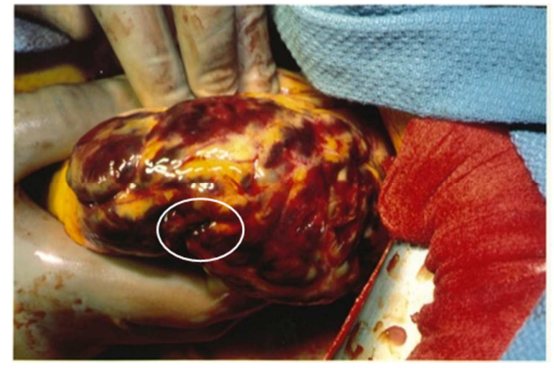

Figure 7. Intra-operative photograph demonstrating diffuse lateral wall myocardial hemorrhage and the linear perforation of the lateral wall (arrow).
1. History: Prolonged - Five days, feeling of agitation and restlessness

2. Examination: Hypotension, no murmur

3. ECG: Significant $\mathrm{Q}$ waves and loss of $\mathrm{R}$ waves in the infero-lateral leads at time of presentation.

\subsection{Case \#3}

Fifty-five-year-old female presented to PCP office 3 days after successful PCI for an acute lateral STEMI. Her initial presentation was 10 hours following onset of pain. ECG revealed sinus arrest, junctional rhythm, ST elevation in the inferior leads as well as Q waves inferiorly (Figure 8). She underwent emergent angiography with a door to balloon time of 55 minutes. The procedure was complicated and required 3 hours to complete. The remainder of the hospital course was uncomplicated and her pre-discharge echo showed an EF of $40 \%$ with an akinetic inferior and infero-septal wall. She was discharged post MI day 3 on beta-blocker, ACE inhibitor, high intensity statin therapy and dual antiplatelet therapy. Two days after discharge she woke with mild shortness of breath but no chest pain. She contacted her PCP and presented to the office for evaluation. She was in mild to moderate respiratory distress. BP 124/86, 88, 24, 93\% RA. No distended JVP and clear lung fields. There was a soft parasternal lift, and a $3 / 6$ holosystolic murmur best heard at the apex. Office ECG revealed inferior $\mathrm{Q}$ waves without $\mathrm{R}$ waves and $2 \mathrm{~mm} \mathrm{ST}$ elevation. Upon presentation to the ER, the Troponin was 3.5 $\mathrm{ng} / \mathrm{ml}$ compared to a pre-discharge of $10.8 \mathrm{ng} / \mathrm{ml}$. An emergent bedside echo showed an akinetic inferior and infero-septal wall with involvement of the posteromedial papillary muscle and moderate to severe mitral valve regurgitation. Emergent coronary angiography revealed a patent stent, and severe mitral regurgitation. An intra-aortic balloon pump was placed and she was taken to the OR for mitral valve replacement.

Clues to the diagnosis:

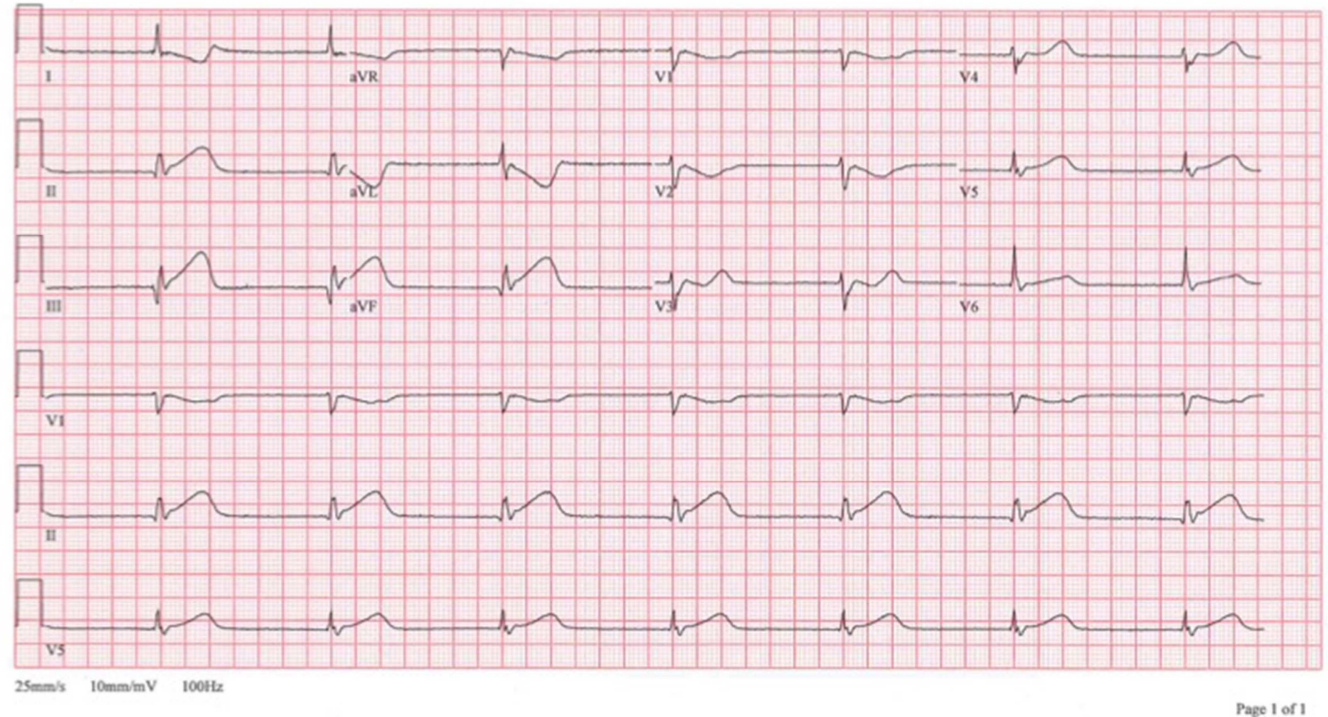

Figure 8. EKG at the initial presentation showing sinus arrest, junctional rhythm and ST elevation with developing $Q$ waves in the inferior wall. 
Clues to the diagnosis of mechanical complication:

1. History: The initial presentation was relatively early compared to cases 1 and 2 however still relatively late and the procedure was complicated requiring 3 hours to complete. There were already $\mathrm{Q}$ waves developing in the inferior leads consistent with the onset of myocardial necrosis. New post MI shortness. Pre-discharge echocardiogram showed akinetic walls most likely representing infarcted segments.

2. Exam: New holosystolic murmur

3. ECG: $\mathrm{Q}$ waves in the inferior leads without $\mathrm{R}$ waves indicating completed infarction.

4. Enzymes: While (+), the trend is down and may represent continued decline from the initial presentation and not indicative of a new coronary event.

\section{Discussion}

Cardiovascular disease (CAD) remains the leading cause of death in the US with a yearly incidence rate of approximately 600 cases per 100,000 people. This results in 500,000 to 700,000 deaths each year [8]. More than $50 \%$ of the deaths occur before a patient reaches a hospital with dysrhythmias and pump failure being the most common etiologies. Once the patient reaches the hospital, survival has improved dramatically with reperfusion therapy. Reperfusion therapy most commonly involves catheter-based revascularization with the minority receiving thrombolytics when PCI cannot be delivered in a timely manner. The key element in preventing permanent myocardial death is the time to reperfusion; "Time is Muscle" slogan. As can be seen in our cases, delayed revascularization is associated with increased myocardial necrosis. The extent of myocardial necrosis can be assessed by the degree of Troponin elevation, development of pathologic Q waves on the ECG and akinetic walls on echocardiography. Myocardial necrosis is the pathologic substrate that results in mechanical complications. The combination of the typical onset of mechanical complications occurring beyond the first 48-72 hours and the shortened hospital stays to $<3$ days results in the majority of post MI mechanical complications occurring after discharge. The PCP must be prepared to assess these patients either as part of a hospital transition visit or in response to a call with common post MI symptoms such as shortness of breath or chest pain. The evaluation should include an assessment of the amount of damage that occurred during the initial presentation. Clues to this include the timing of presentation, degree of enzyme elevation, Q waves on the post revascularization and pre-discharge ECG as well as the pre-discharge echocardiogram. In the MILIS study it was found that these mechanical complications were 9.2 times more likely to occur in a patient who had no prior history of coronary disease (angina or myocardial infarction), ST segment elevation, Q wave present on the initial EKG and a peak CK-MB above 150 IU/L [9]. The office assessment includes a detailed history, exam and ECG. Rapid detection and triage are the key to survival. The three major mechanical complications are exemplified in our cases with further details of each outlined below.

Ventricular free wall rupture (VFWR) is the least likely of the mechanical complications but the most lethal. It accounts for approximately $20 \%-30 \%$ of mortality in patients presenting with MI who reach the hospital [10]. It most commonly presents between post MI days 1 to 14 . The timing of this mechanical complication can be in the first 24-48 hours if the patients' initial presentation was delayed as seen in our $2^{\text {nd }}$ case. Late reperfusion beyond the time of salvage of any viable myocardium has an increased incidence of rupture, more commonly by thrombolytic therapy than catheter-based revascularization. It is for this reason there is a general time limit on the class I indication of $<12$ hours for revascularization in a STEMI and a Class IIa for patients 12-24 hours with ongoing ischemia. No recommendation is provided for the timing of intervention $>24$ hours due to the concern for increased complications such as "no-reflow" phenomenon and perforation [11]. VFWR has also been associated in patients with no prior history of angina likely due to acute thrombosis on a pre-existing coronary obstruction of less than $70 \%$. Prior ischemia to an area of subsequent infarction has been associated with a phenomenon called ischemic pre-conditioning which may protect the myocardium from acute necrosis in the setting of acute absence of blood flow as in a STEMI $[12,13]$. Other risk factors associated with VFWR include female and elderly patients.

The clinical presentation is classically with sudden chest pain in the post MI setting between Day 3-10. Reports have described this complication to be clinically predictable. Oliva et al [14] describe LV rupture to be preceded by chest pain consistent with pericarditis, unprovoked emesis and a feeling of restlessness and agitation. More than $80 \%$ of patients had at least two of these symptoms preceding rupture as compared to only $3 \%$ in a comparison group without rupture. Case \#2 nicely describes this constellation of symptoms. Symptoms likely start during the initial tear from the ventricular cavity through the necrotic myocardium. A rapid complete rupture will lead to hemopericardium, cardiac tamponade, cardiogenic shock and death within a matter of minutes. Incomplete ruptures present with the clinical symptoms mentioned above but do not have acute rupture into the pericardial sac. This occurs due to the pericardium restricting complete rupture. These patients can often have abrupt, transient hypotension, bradycardia and alterations of the $\mathrm{T}$ waves. It is during this time period that rapid identification and triage may save the patient's life. Left unrecognized the process will progress to hemopericardium and death or rarely remain contained resulting in a pseudoaneurysm. The PCP's clues when reviewing an EKG that should raise suspicion of a free wall rupture include pathologic Q wave and persistent ST elevation. Most importantly, when suspected, emergent cardiology evaluation with echocardiogram can be lifesaving.

Interventricular septum rupture is the most common mechanical complication accounting for $75 \%$ of cases. Unlike VFWR, It can occur with any of the 3 major coronary 
occlusions and depends on the vasculature supplying the interventricular septum. The anterior portion is supplied by the LAD while the posterior portion can be fed by either the RCA or circumflex depending on which is the dominant vessel It occurs 1-14 days post -MI and can have a bimodal incidence [10]. It occurs early, within the first 24 hours when reperfusion is provided in the setting of delayed presentation beyond 12 hours. Revascularization is done beyond 12 hours when continued ischemia is suspected. Presentation starting day 3 post MI should be suspected when the presenting myocardial infarction is associated with significant myocardial necrosis. Risk factors shown to be associated with VSD include single vessel disease, first MI, older age and extensive myocardial damage (10). Patients may be asymptomatic early on but have a new soft holosystolic murmur. This is usually followed by recurrent chest pain, pulmonary edema, hypotension or cardiogenic shock as the VSD enlarges and the shunt from left to right increases. When the VSD is small and the shunt less than a pulmonary to systemic blood flow ratio $(\mathrm{Qp} / \mathrm{Qs})<1.5 / 1$ the physical exam will have pansystolic murmur (best heard at the left lower sternal border), potentially accompanied by a thrill. A larger VSD with a Qp/Qs $>1.5 / 1$ will result in pulmonary edema, pulmonary hypertension, tachycardia, and systemic hypotension. As the pressure gradient between the left and right ventricular becomes smaller, the murmur intensity becomes less and may no longer be holosystolic. The signs of pulmonary edema with become more prominent and a tachycardic gallop may be all that can be heard. Emergent cardiology, cardiovascular surgery consultation and echocardiogram are essential and like all of the post MI mechanical complications, lifesaving. Surgery has been shown to be possible and lifesaving for more than 40 years [15] with the current recommendation that surgery should be emergently performed and not delayed. The PCP should investigate all holosystolic murmurs post MI regardless of the presence or absence of symptoms. The differential diagnosis would be a ventricular septal defect or mitral insufficiency and both can progress rapidly. Clues to suspect this mechanical complication are those associated with later or incomplete revascularization which will be evident by reviewing the hospital course of the initial presentation or if confronted with the initial presentation then the history, exam and ECG should help with the diagnosis.

Papillary muscle rupture is challenging for the clinician because some degree of mitral insufficiency is common post myocardial infarction and mild to moderate can be seen in up to $45 \%$ of patients [16]. It occurs in $0.26 \%$ of MI's in the era of reperfusion. However, like free wall rupture and acquired VSD it should be suspected in the patient with late presentation or incomplete revascularization. Without diagnosis and emergent surgery, the mortality can be as high as $50 \%[10]$. It is more common with an inferior, posterior or infero-posterior MI. Risk factors include prior history of CAD, female gender, increase age, RCA lesion with right dominant circulation. Papillary muscle rupture should be suspected in a patient presenting with new or worsening symptoms of shortness of breath beyond 48 hours post MI. This is the result of the increased left atrial and pulmonary venous pressure from mitral insufficiency. Rarely does the entire muscle rupture without prodromal symptoms of shortness of breath ranging from hours to days in duration. A soft holosystolic murmur of mitral insufficiency can be heard commonly post MI but it should not become louder or associated with signs of volume overload such as an associated gallop, diastolic rumble, loud pulmonary component of the second heart sound or a parasternal lift. Severe or complete rupture will be associated with the sudden onset of pulmonary edema and cardiogenic shock. When this occurs, the diagnosis can be a challenge by physical exam. The diagnostic murmur of mitral insufficiency will become barely audible due to equalization of left ventricular and left atrial pressures. The clinical exam will be that of cardiogenic shock. Emergent echocardiography by TTE and if non-diagnostic TEE will make the diagnosis with a sensitivity of almost $100 \%$. These patients can be stabilized by intubation, placement of an intra-aortic balloon pump allowing surgical repair.

Table 1 provides a summary of the three mechanical complications that may present to the outpatient primary care physicians office:

Table 1. References 8, 10, 11, 13-15

\begin{tabular}{|c|c|c|c|}
\hline & Free left ventricular wall rupture & Ventricular septum rupture & Papillary muscle rupture \\
\hline $\begin{array}{l}\text { Percent of mechanical } \\
\text { complications in the } \\
\text { reperfusion era }\end{array}$ & $3 \%$ & $75 \%$ & $22 \%$ \\
\hline Time to occur & $\begin{array}{l}\text { 1-14 days. } \\
50 \% \text { presents within } 5 \text { days and } 90 \% \text { within } \\
\text { first } 2 \text { weeks. }\end{array}$ & $\begin{array}{l}\text { 1-14 days MI } \\
\text { Can present with a bimodal pattern: First } \\
24 \text { hours or } 3-5 \text { days post-MI. }\end{array}$ & $\begin{array}{l}\text { 2-7 days after MI } \\
\text { Can be earlier due to increased stress } \\
\text { placed on papillary muscle with } \\
\text { hypertension or tachycardia }\end{array}$ \\
\hline
\end{tabular}




\begin{tabular}{|c|c|c|c|}
\hline & Free left ventricular wall rupture & Ventricular septum rupture & Papillary muscle rupture \\
\hline & $\begin{array}{l}\text { rupture) } \\
\text { Recurrent sudden chest pain. } \\
\text { Signs and symptoms of cardiac tamponade } \\
\text { (SOB, lightheadedness, palpitations, leg } \\
\text { swelling, etc). } \\
\text { Sudden death }\end{array}$ & $\begin{array}{l}\text { Symptoms of pulmonary edema (SOB, } \\
\text { orthopnea, tachypnea, etc) } \\
\text { Lightheadedness } \\
\text { Cardiogenic shock. }\end{array}$ & Cardiogenic shock. \\
\hline Physical findings & $\begin{array}{l}\text { Tachycardia } \\
\text { JVD } \\
\text { Hypotension } \\
\text { Distant heart sounds. } \\
\text { Nausea } \\
\text { Diaphoresis }\end{array}$ & $\begin{array}{l}\text { New systolic murmur } \\
\text { Early onset, small VSD - holosystolic } \\
\text { Large VSD - low pitched, early systolic } \\
\text { S3 } \\
\text { Palpable parasternal thrill. } \\
\text { Pulmonary rales } \\
\text { Signs of acute right heart failure } \\
\text { JVD } \\
\text { Tricuspid regurgitation with giant V } \\
\text { waves. } \\
\text { Hepatojugular reflux. } \\
\text { Low peripheral perfusion (slow capillary } \\
\text { refill, cold extremities, faint distal pulses) }\end{array}$ & $\begin{array}{l}\text { Holosystolic murmur: This may be loud or } \\
\text { barely audible depending on the difference } \\
\text { between LV and LA pressure. Low } \\
\text { systemic pressure and high LA pressure } \\
\text { will result in a less intense decrescendo } \\
\text { murmur with a tachycardic gallop. } \\
\text { Pulmonary rales } \\
\text { Low peripheral perfusion (slow capillary } \\
\text { refill, cold extremities, faint distal pulses) }\end{array}$ \\
\hline EKG & $\begin{array}{l}\text { Persistent or recurrent ST elevations. } \\
\text { Q waves. } \\
\text { Low voltage or electrical alternans. }\end{array}$ & $\begin{array}{l}\text { Significant } Q \text { waves involving either the } \\
\text { anterior or inferior walls }\end{array}$ & $\begin{array}{l}\text { Significant } Q \text { waves most commonly in } \\
\text { the inferior leads. }\end{array}$ \\
\hline Echocardiogram & $\begin{array}{l}\text { Pericardial effusion / tamponade } \\
\text { Segmental systolic dysfunction with focal } \\
\text { disruption of the myocardial wall }\end{array}$ & $\begin{array}{l}\text { Akinetic septal wall with left to right } \\
\text { shunting on color Doppler } \\
\text { Signs of pulmonary hypertension. } \\
\text { RV dilation. }\end{array}$ & $\begin{array}{l}\text { Eccentric mitral regurgitation on color } \\
\text { Doppler due to partial or completely flail } \\
\text { mitral valve leaflet/papillary muscle into } \\
\text { atrium during systole. }\end{array}$ \\
\hline Vessel affected & LAD and LCX & LAD, dominant RCA or dominant $\mathrm{LCx}$ & RCA/PDA \\
\hline
\end{tabular}

\section{Summary}

Current care of the STEMI patient includes early discharge. This makes the still seen mechanical complications more likely to occur in the outpatient setting. The PCP should be familiar with how to assess the risk for this rare but fatal complication as well as clues on when to have a high index of suspicion. Knowledge of the assessment of the extent of myocardial damage by review of the historical data, enzyme elevation, ECG and echocardiogram are essential. The key common pathologic state is delayed, difficult or incomplete revascularization. This results in more extensive myocardial necrosis, which increases the risk for all of the mechanical complications. These cases illustrate the clinical presentation and approach to these patients.

\section{References}

[1] Thompson CR, Buller CE, Sleeper LA, Antonelli TA, Webb JG, Jaber WA, et al. Cardiogenic shock due to acute severe mitral regurgitiation complicating acute myocardial infarction: a report from the SHOCK Trial Registry. J Am Coll Cardiol 2000; 36 (3 Suppl A): 1104-9.

[2] Poulsen SH, Praestholm M, Munk K, Wierup P, Egeblad H, Nielsen-Kudsk JE. Ventricular septal rupture complicating acute myocardial infarction: clinical characteristics and contemporary outcome. Ann Thorac Surg 2008; 85 (5): 1591-6.

[3] Menon V, Webb JG, Hillis LD, Sleeper LA, Abboud R, Dzavik $\mathrm{V}$, et al. Outcome and profile of ventricular septal rupture with cardiogenic shock after myocardial infarction: a report from the SHOCK Trial Registry. J Am Coll Cardiol 2000; 36 (3 Suppl A): 1110-6.
[4] Elbadawi A, Elgendy IY, Mahmoud K, Barakat AF, Mentias A, et al. Temporal Trends and Outcomes of Mechanical Complications in Patients with Acute Myocardial Infarction. J Am Coll Cardiol Intv 2019; 12: 1825-1836.

[5] Herrick JB, Nuzum FR. Angina pectoris: Clinical experience with two hundred cases. J Am Med Assoc. 1918; 70 (2): 67-70.

[6] Levine SA, Lown B. "Armchair" treatment of acute coronary thrombosis. J Am Med Assoc. 1952; 148 (16): 1365-1369.

[7] Vavalle JP, Lopes RD, Chen AY, et al. Hospital length of stay in patients with non-st-segment elevation myocardial infarction. Am J Med. 2012; 125 (11): 1085-1094.

[8] Myocardial Infarction: Practice Essentials, Background, Definitions.

https://emedicine.medscape.com/article/155919-overview\#a6. Accessed March 26, 2020

[9] Acute myocardial infarction: Mechanical complications UpToDate.

https://www.uptodate.com/contents/acute-myocardial-infarctio n-mechanical-complications?source=history widget. Accessed March 26, 2020.

[10] Montrief T, Davis WT, Koyfman A, Long B. Mechanical, inflammatory, and embolic complications of myocardial infarction: An emergency medicine review. Am J Emerg $\begin{array}{lllll}\text { Med. } 2019 ; & 37 & \text { (6): } 1175-1183 . & \text { doi: }\end{array}$ 10.1016/j.ajem.2019.04.003

[11] O'Gara PT, Kushner FG, Ascheim DD, Casey DE, Chung MK, et al. 2013 ACCF/AHA Guideline for the Management of ST-Elevation Myocardial Infarction. J Am Coll Cardiol 2013; 61 (4): e78-e140.

[12] Laskey WK, Beach D. Frequency and Clinical Significance of Ischemic Preconditioning During Percutaneous Coroanry Intervention. J Am Coll Cardiol 2003; 42 (6): 998-1003. 
[13] Kloner RA, Shook T, Przyklenk K, et al. Previous angina alters in-hospital outcome in TIMI-4; a clinical correlate to preconditioning. Circulation 1995; 91: 37-45.

[14] Oliva PB, Hammill SC, Edwards WD. Cardiac Rupture, a Clinically Predictable Complication of Acute Myocardial Infarction: Report of 70 Cases with Clinicopathologic Correlations. J Am Coll Cardiol 1993; 22: 720-726)

[15] Montoya A, McKeever L, Scanlon P, Sullivan HJ, Gunnar RM, Pifarre R. Early repair of ventricular septal rupture after infarction. Am J of Cardiology 1980; 45 (2): 345-348.
[16] Aronson D, Goldsher N, Zukermann R, Kapeliovich M, Lessick J, et al. Ischemic mitral regurgitation and risk of heart failure after myocardial infarction. Arch Intern Med 2006; 166 (21): 232-8.

[17] Barbour DJ, Roberts WC. Rupture of a left ventricular papillary muscle during acute myocardial infarction: Analysis of 22 necropsy patients. J Am Coll Cardiol 1986; 8 (3): 558-565. 